\title{
TOPICS IN MEDICAL EDUCATION ELECTIVE BLOCK: A STUDY USING DELPHI METHOD
}

\author{
Geraldo ${ }^{1}$, Elisabeth Rukmini ${ }^{1 *}$ \\ ${ }^{1}$ Medical Education Unit, Fakultas Kedokteran \& IImu Kesehatan Universitas Katolik Indonesia Atma Jaya, Jakarta - INDONESIA
}

\begin{abstract}
Background: Problematic practices performed by doctors and clinical phase students often be found in the workplace settings. Common problems related to team working is the highest rated problems. To overcome this problem, we designed an elective course, Medical Education block (ME) and have implemented the course since 2014. This study aimed to find topics in ME which were meaningful toward medical student's practices.
\end{abstract}

Methods: A Delphi method were utilized. The experts were the subjects themselves to acknowledge that they were the participants of the ME block, other elective blocks, and clerkship. There were 21 respondents consisted of 2012, 2013 and 2014 bathces. All the subjects were in their clerkship or at the end of their education. They were divided into two groups: who enrolled in $\mathrm{ME}(n=10)$, and other blocks $(n=11)$. The questionnaire was consisted of three parts. The first part listed 5 main topics with responses of agree/disagree. The second part listed the same topics, but subjects needed to response the weight on each topic. The last part listed 27 topics in ME Block that might or might not relate to clerkship. Responses were given in agree/disagree.

Results: Using two-rounded Delphi method, we found the average of rate of agreement (roa) on the first round was $88 \%$ and the second was $81 \%$. There were only 2 statements of the second part which had roa $>70 \%$. Thus, the second part went to the $2^{\text {nd }}$ round together with the 3 statements of the third parts. Finally, there were only 2 statements of the second parts achieved roa and there were 2 topics left undecided of the third part.

Conclusion: Few topics which were proven useful for medical students were personal education, medical education research, and professionalism.

Keywords: practices, medical education, elective course

\section{ABSTRAK}

Latar belakang: Praktik dokter atau mahasiswa klinik seringkali problematik terutama pada masalah kerja sama dalam tim. Untuk menemukan solusi terhadap masalah itu, kami mendesain blok elektif Ilmu Pendidikan Kedokteran (IPK) yang diimplementasikan sejak 2014. Tujuan penelitian ini untuk menemukan topik-topik dalam blok IPK yang bermakna bagi praktik mahasiswa kedokteran di tingkat klinik.

Metode: Metode Delphi digunakan dalam penelitian ini. Pakar dalam metode ini adalah para subjek yang mengikuti blok IPK, blok elektif lain, dan pendidikan klinik. Terdapat 21 subjek dari angkatan 2012, 2013, dan 2014 yang sedang menempuh tingkat klinik ataupun dalam masa akhir studi kedokteran menunggu masa magang. Subjek dibagi menjadi dua kelompok yaitu peserta blok IPK $(\mathrm{N}=10)$ dan peserta blok elektif lainnya $(\mathrm{N}=11)$. Kuesioner terbagi menjadi tiga bagian. Bagian pertama terdiri dari 5 topik blok IPK yang dekat dengan praktik klinik. Respon bagian pertama setuju/tidak setuju. Bagian kedua sama dengan bagian pertama kecuali ada pembobotan. Bagian ketiga terdiri dari 27 topik dalam blok IPK yang mungkin berkaitan dengan tingkat klinik. Respon sebagai setuju/tidak setuju.

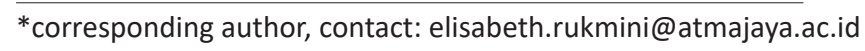


Hasil: Delphi dilakukan dua putaran. Dalam putaran pertama ditemukan rerata tingkat persetujuan, rate of agreement, (roa) $88 \%$, sedangkan putaran kedua $81 \%$. Hanya terdapat 2 pernyataan bagian kedua yang roa $>70 \%$. Karenanya, seluruh bagian 2 dan 3 pernyataan bagian ketiga dilanjutkan ke putaran kedua. Hasil akhir menunjukkan hanya 2 pernyataan dari bagian kedua yang memenuhi roa dan terdapat 2 topik dari bagian 3 tidak dapat diputuskan.

Kesimpulan: Topik-topik yang terbukti berguna dan bermakna bagi praktik kedokteran adalah edukasi personal, penelitian pendidikan kedokteran, dan profesionalisme.

Kata kunci: praktik, Ilmu Pendidikan Kedokteran, blok elektif

\section{PENDAHULUAN}

Praktik dokter dalam dunia klinik ataupun dunia kerja semakin tampak perlunya team working. Riset mengenai team-working dalam kaitannya dengan profesionalisme di dunia kerja bidang kedokteran dan kesehatan telah banyak dilakukan. ${ }^{1-4}$ Demikian pula dengan intervensi pendidikan kedokteran yang dilakukan untuk melatih mahasiswa kedokteran dalam bekerja bersama tim termasuk yang lintas profesi. $^{5-7}$ Tujuan utama intervensi serupa untuk melatih mahasiswa kedokteran hingga mampu menghadapi dunia kerja di klinik yang beragam dan membutuhkan kerja sama yang erat antar pelakunya. Keengganan komunikasi, perilaku yang tidak terbiasa bekerja dalam tim, tindakan yang biasa dilakukan dan diputuskan sendiri kerap kali menjadi hambatan dalam teamworking. Dampaknya, permasalahan dalam kerja berujung pada layanan bagi pasien.

Penelitian mengenai intervensi pendidikan di tingkat pre-klinik untuk solusi bagi masalah kerja dalam tim di tingkat klinik dilakukan dengan berbagai cara. Penerapan yang sifatnya masif dan menyangkut bencana alam telah dilakukan ${ }^{5}$; hasil penelitian menunjukkan sifat kolaborasi, negosiasi, komunikasi meningkat setelah pelatihan. Intervensi pendidikan juga dilakukan pada bidangbidang yang spesifik seperti pada perawatan lansia di komunitas, pengukuran persepsi dan sikap terhadap mahasiswa kedokteran dan kesehatan dilakukan sebagai pre- dan pos-tes. ${ }^{6}$ Studi tersebut di atas menunjukkan intervensi dan investigasi dampak intervensi dilakukan dengan kualitatif ataupun kuantitatif.
Intervensi team working dalam pendidikan yang dilakukan di tingkat klinik, meskipun tepat dalam kerangka tempat kerja, namun cukup terlambat bila dipandang dari kesiapan kerja. Oleh karena itu, intervensi pendidikan tingkat pre-klinik dengan integrasi team working pada mata kuliah tertentu menjadi krusial. Upaya mengintegrasikan materi terkait team working dan materi-materi yang dipandang akan bermakna pada tingkat klinik dilakukan oleh Fakultas Kedokteran dan Ilmu Kesehatan Universitas Katolik Indonesia Atma Jaya (FKIKUAJ). Blok elektif Ilmu Pendidikan Kedokteran (blok IPK) merupakan materi yang integratif antara aspek pendidikan, hubungan antar profesi, profesionalisme, kolaborasi, komunikasi bagi komunitas melalui media, riset pendidikan kedokteran. Blok IPK ada di semester 7 (tahun ke-4) dengan bobot 5 SKS dan lama waktu pembelajaran 5 minggu. Blok elektif IPK dibuat agar mahasiswa mengenal berbagai aspek teoritis dan praktis dari proses pembelajaran ilmu kedokteran untuk diaplikasikan dalam kehidupan sehari-hari agar terbentuk sikap belajar sepanjang hayat, dan memberikan gambaran kepada mahasiswa bahwa proses belajar dan mengajar adalah tindakan sosial. Penelitian terdahulu menunjukkan topik-topik yang telah terbukti bermanfaat untuk mahasiswa pada tahap klinik yaitu adult learning theory, self-directed learning (SDL), profesionalisme, dan Interprofesional Collaboration (IPC). ${ }^{9,10}$

Adult learning theory membantu mahasiswa mengidentifikasi hal penting suatu bahan ajar, serta mengaitkan pengalaman dan ilmu-ilmu yang telah dipelajari sebelumnya. ${ }^{10,11}$ Belajar mandiri atau Selfdirected learning (SDL) memerlukan motivasi belajar 
dari diri sendiri. SDL penting untuk menciptakan gaya belajar sepanjang hayat karena perkembangan ilmu kedokteran yang sangat dinamis. Christian Medical College membuat metode SDL menjadi budaya dan kurikulum dominan dalam sistem perkuliahannya. ${ }^{10}$ Profesionalisme merupakan dasar kompetensi dalam profesi kedokteran di dunia, dan dibutuhkan juga oleh mahasiswa saat mencapai tingkat klinik. Suatu penelitian yang dilakukan di Kuwait University menunjukkan bahwa mayoritas mahasiswa (77,6\%) berpendapat kurikulum mereka seharusnya menguji profesionalisme pada mahasiswa kedokteran, agar dapat menjadi dasar pertimbangan dalam penilaian karir seseorang. ${ }^{9}$ IPC merupakan kunci utama dalam memberikan pelayanan terpadu kepada pasien. IPC merupakan kelompok yang terdiri dari beberapa profesi dan bertujuan untuk menjawab masalah/keluhan dari pasien/keluarga/komunitas. ${ }^{6}$

Untuk mengetahui topik-topik apa saja dalam blok IPK yang berpengaruh terhadap sikap dan perilaku mahasiswa dan lulusan kedokteran FKIK UAJ, perlu dilakukan analisis sikap dan perilaku untuk mahasiswa yang telah mengikuti blok elektif Ilmu Pendidikan Kedokteran (IPK) dan blok elektif selain blok IPK. Tujuan penelitian ini secara umum adalah mengetahui topik-topik blok elektif Ilmu Pendidikan Kedokteran (IPK) yang mempengaruhi sikap dan perilaku mahasiswa dan lulusan kedokteran. Secara khusus, penelitian ini mencoba membandingkan topik-topik apa saja dalam blok IPK yang pengaruh terhadap sikap dan perilaku mahasiswa dan lulusan kedokteran, yang mengambil blok elektif IPK dan selain blok elektif IPK.

\section{METODE}

Penelitian ini berkaitan dengan mahasiswa yang pernah mengambil mata kuliah elektif di FKIK UAJ. Blok elektif di FKIK UAJ terdiri dari empat pilihan, yaitu: Blok Entrepreneurship Bidang Kesehatan, Blok Kedokteran Adiksi, Blok Palitiatif, dan Blok IPK. Blok elektif dipilih oleh mahasiswa pada semester VII. Blok IPK disusun agar mahasiswa mengenal berbagai aspek teoritis dan praktis dari proses pembelajaran ilmu kedokteran untuk diaplikasikan dalam kehidupan sehari-hari agar terbentuk sikap belajar sepanjang hayat, dan memberikan gambaran kepada mahasiswa bahwa proses belajar dan mengajar adalah tindakan sosial.

Penelitian ini merupakan penelitian kualitatif yang menggunakan metode Delphi untuk menelusuri topik-topik apa saja yang berpengaruh terhadap sikap dan perilaku mahasiswa dan lulusan dokter dalam pekerjaan di klinik, serta membandingkan topik-topik yang berpengaruh tersebut menurut mahasiswa yang mengambil blok elektif IPK, dan selain blok elektif IPK (adiksi, paliatif, dan entrepreneurship bidang kesehatan). Pakar dalam metode ini adalah para subjek yang mengikuti blok IPK, blok elektif lain, dan pendidikan klinik.

Responden diambil secara purposive sampling dengan teknik snowballing sesuai dengan kriteria inklusi, yaitu mahasiswa kedokteran (angkatan 2013 dan 2014) dan lulusan kedokteran (angkatan 2012), mengikuti tahap pendidikan klinik, bersedia mengikuti penelitian dan mengisi informed consent. Terdapat 21 subjek dari angkatan 2012, 2013, dan 2014 yang sedang menempuh tingkat klinik ataupun dalam masa akhir studi kedokteran menunggu masa magang. Subjek dibagi menjadi dua kelompok yaitu peserta blok IPK $(\mathrm{N}=10)$ dan peserta blok elektif lainnya $(\mathrm{N}=11)$.

Kuesioner Delphi berisikan 32 topik bidang Ilmu Pendidikan Kedokteran yang diambil dari buku teks Understanding Medical Education karya Swanwick et al. ${ }^{12}$ Kuesioner Delphi dibagi menjadi 3 bagian:

1. Bagian 1, terdiri dari 5 topik, model pertanyaan setuju/tidak setuju, mengenai apakah topiktopik yang diajarkan di blok IPK berpengaruh pada perilaku subjek.

2. Bagian 2, terdiri dari 8 poin, model pertanyaan adalah bobot, mengenai pertanyaan bagian 1 tentang sejauh mana pengaruh topik tersebut terhadap perilaku mahasiswa di tingkat klinik atau dalam praktik dokter. Jawaban terdiri dari bobot 1 sampai 3, bobot 3 menandakan topik tersebut paling berpengaruh terhadap perilaku subjek.

3. Bagian 3, terdiri dari 27 topik, model pertanyaan setuju/tidak setuju, mengenai topik-topik selain bagian 1 yang menurut responden berpengaruh terhadap perilaku mahasiswa kedokteran. 
Penentuan rate of agreement (roa) pada penelitian ini adalah sebesar $\geq 70 \%$, Delphi dilakukan dalam dua putaran. Putaran pertama berisi pertanyaan dari bagian 1, 2 dan 3. Untuk Delphi putaran kedua berisi pernyataan yang tidak mencapai roa $\geq 70 \%$ dan pertanyaan bagian 2 untuk melihat perbedaan bobot dari putaran pertama dan kedua.

\section{HASIL DAN PEMBAHASAN}

Hasil Delphi dibagi menjadi hasil putaran I dan II. Hasil Delphi putaran pertama menunjukkan, hanya 3 topik dari 32 topik yang tidak mencapai roa $\geq 70 \%$. Hasil ini menunjukkan bahwa semua mahasiswa maupun lulusan, baik yang mengambil blok elektif IPK dan selain blok IPK setuju pada topik-topik yang diajarkan dapat mempengaruhi perilaku mahasiswa kedokteran dan lulusan dalam praktik di klinik, rincian topik IPK dapat dilihat di Tabel 1. Tiga topik yaitu: (1) Desain kurikulum, (2) Learning medicine from humanities, (3) Lectures for large groups; tidak disepakati dalam putaran pertama. Pada akhir putaran kedua, hanya satu dari ketiga topik itu, Learning medicine from humanities, yang disepakati oleh subjek sebagai topik IPK yang berpengaruh di klinik (roa $80 \%$ ).

Tabel 1. Daftar topik-topik blok elektif IPK

\section{Topik}

- Teori belajar dan aplikasi teori belajar

- Metode pembelajaran berdasarkan adult learning theory

- Penelitian pendidikan kedokteran

- Edukasi personal dan pemberian constructive feedback

- Profesionalisme dan Interprofesional Collaboration (IPC)

- Desain kurikulum

- Problem-based learning (PBL)

- Kolaborasi antar bidang ilmu untuk problem solving, Interprofessional Education (IPE)

- Work-based learning

- Learning medicine from humanities

- Portofolio, personal development, dan reflective practice

- Mentorship

- Teaching and leading in small groups (<30 orang)

- Lectures for large groups (>30 orang)

- Online and e-learning

- Belajar dengan simulasi

- Probandus dalam pendidikan kedokteran

- Asesmen dalam pendidikan kedokteran

- Desain asesmen \& tujuan pembelajaran

- Asesmen dalam lingkungan klinis (saat koas)

- Objective Structured Clinical Examinations (OSCE)

- Belajar mandiri, atau self-regulated learning

- Implementasi penelitian ilmiah dalam pendidikan kedokteran

- Quantitative research methods

- Qualitative research methods

- Penerapan Evidence based medicine

- Seleksi masuk dan lulus di dunia kedokteran

- Sistem remedial dalam kedokteran

- Pendidikan kedokteran yang berkualitas (ilmiah, estetik, pengelolaan, etis, profesional)

- Ragam bahasa, stereotip dan budaya dan kaitannya dengan kedokteran

- Dosen sebagai perencana kurikulum, penilai, pembimbing mahasiswa, dan peneliti

- Sikap kepemimpinan dalam pendidikan kedokteran roa Putaran I (Putaran II)

$81 \% *$

$90 \%$

$90 \%$

$76 \% * *$

$95 \% * * *$

$48 \%(52 \%)$

$90 \%$

$81 \%$

$76 \%$

$62 \%(81 \%)$

$71 \%$

$85 \%$

$81 \%$

28\% (52\%)

$76 \%$

$95 \%$

$95 \%$

$76 \%$

$100 \%$

$90 \%$

$85 \%$

$95 \%$

$95 \%$

$90 \%$

$76 \%$

$100 \%$

$95 \%$

$95 \%$

$100 \%$

$85 \%$

$95 \%$

$100 \%$

* Total setuju dari dua topik gabungan menjadi "Teori belajar dan aplikasi teori belajar".

** Total setuju dari dua topik gabungan menjadi "Edukasi personal dan pemberian constructive feedback".

*** Total setuju dari dua topik gabungan menjadi "Profesionalisme dan Interprofesional Collaboration (IPC). 
Hasil Delphi hingga putaran kedua menyisakan dua topik yang tidak mendapatkan kesepakatan subjek sebagai topik yang berpengaruh dalam dunia klinis. Kedua topik itu adalah desain kurikulum dan lectures for large groups. Di akhir Delphi putaran kedua juga didapati topik-topik yang dianggap oleh subjek sebagai paling berpengaruh pada perilaku mahasiswa dan lulusan adalah: (1) edukasi personal (roa 81\%), (2) penelitian pendidikan kedokteran (roa 71\%), dan (3) profesionalisme (roa 71\%). Ketiga topik ini disepakati oleh mahasiswa dan lulusan kedokteran yang mengambil blok IPK maupun yang mengambil blok elektif lainnya.
Secara spesifik terdapat perbedaan pendapat mengenai topik yang berpengaruh menurut mahasiswa maupun lulusan kedokteran baik yang mengambil blok elektif IPK dan selain blok IPK. Bagi mahasiswa dan lulusan blok IPK, terdapat empat topik yang dipandang sangat berpengaruh pada praktik di klinik dengan roa $\geq 70 \%$ (Tabel 2). Sementara bagi mahasiswa dan lulusan kedokteran yang mengambil blok elektif selain IPK sepakat pada tiga topik: edukasi personal, profesionalisme, dan penelitian pendidikan kedokteran. Titik perbedaan terdapat pada topik IPC.

Tabel 2. Rate of agreement (roa) topik-topik yang berpengaruh menurut peserta blok elektif

\begin{tabular}{lccccc}
\multicolumn{1}{c}{$\begin{array}{c}\text { Topik } \\
\text { Blok }\end{array}$} & $\begin{array}{c}\text { Edukasi } \\
\text { Personal }\end{array}$ & $\begin{array}{c}\text { Penelitian } \\
\text { Pendidikan } \\
\text { Kedokteran }\end{array}$ & $\begin{array}{c}\text { Pemberian } \\
\text { Constructive } \\
\text { Feedback }\end{array}$ & Profesionalisme & $\begin{array}{c}\text { Inter-professional } \\
\text { collaboration (IPC) }\end{array}$ \\
IPK (N=10) & $80 \%$ & $70 \%$ & $60 \%$ & $70 \%$ & $70 \%$ \\
Non IPK (N=11) & $82 \%$ & $73 \%$ & $27 \%$ & $73 \%$ & $36 \%$ \\
\hline
\end{tabular}

Topik edukasi personal dianggap penting oleh mahasiswa dan lulusan kedokteran baik yang mengambil blok IPK dan selain blok IPK. Mahasiswa kedokteran perlu merancang edukasi personal saat ingin memberikan edukasi kepada pasien, dengan memperhatikan aspek-aspek tertentu seperti: usia, pekerjaan, tingkat pendidikan, akses informasi, kenyamanan pasien, metode edukasi. Secara hakikat, layanan yang berpusat pada pasien telah menjadi arus utama dalam bidang kedokteran dan kesehatan. Dalam riset ini, mahasiswa kedokteran merasakan pentingnya edukasi personal berbasis pada pengalaman mereka di tingkat klinik. Dalam artian ini, mahasiswa menyadari dari pengalaman yang masih bertumbuh, niat untuk berfokus pada layanan perorangan pasien sudah nampak. Meskipun demikian, bila dikaitkan dengan penelitian terdahulu, kesadaran ini cukup ironis karena menurunnya empati pada layanan yang berpusat pada pasien. ${ }^{12,13}$ Menanggapi kondisi ini, suatu usulan berupa perlunya penulisan narasi berbasis pengalaman riil para tenaga kesehatan yang berpusat pada pasien dapat ditempuh dalam pendidikan kedokteran. ${ }^{14,15}$ Dalam blok IPK di Unika Atma Jaya, edukasi personal nyata diperlihatkan melalui kunjungan dan keterlibatan mahasiswa kedokteran dalam dua tipe layanan kesehatan berbasis komunitas yaitu di Yayasan Orangtua Peduli (YOP) dan Komunitas Putri Kasih di Cilincing. Edukasi personal berpusat pada pasien dengan demikian telah menemukan maknanya melalui karya nyata orang-orang yang terlibat sedikitnya dari dua contoh tersebut.

Profesionalisme juga penting karena sikap dan perilaku yang baik dalam profesi kedokteran adalah menghormati teman sejawat dan pasien, bertanggung jawab, mengutamakan etika, keterampilan dalam berkomunikasi, dan refleksi diri. ${ }^{9,15}$ Penelitian yang dilakukan di Kuwait University menunjukkan bahwa mayoritas mahasiswa $(77,6 \%)$ berpendapat kurikulum mereka seharusnya menguji profesionalisme pada mahasiswa kedokteran, agar dapat menjadi dasar pertimbangan dalam penilaian karir seseorang. ${ }^{9}$

Penelitian dalam pendidikan kedokteran merupakan topik yang juga dipandang penting oleh peserta blok IPK maupun non-IPK. Proses berpikir sistematik memang penting dilakukan oleh mahasiswa karena pengalaman saat melakukan penelitian 
seperti berpikir, menulis dan menelusuri sebabakibat dari suatu masalah dapat melatih berpikir kritis, kreatif menemukan solusi dan berbasis data. Perkembangan penelitian pendidikan kedokteran dalam beragam fase sebenarnya juga mendorong perkembangan arah pendidikan kedokteran agar sejalan dengan perkembangan bidang kedokteran dan kesehatan. ${ }^{16} \mathrm{Ji}$ dan kelompok penelitiannya, menginterpretasikan hasil dari social network analysis (SNA) atas fase pertumbuhan penelitian pendidikan kedokteran, saat ini dalam fase yang mereka sebut sebagai expansion phase (20062015). Penelitian pendidikan kedokteran dengan demikian telah pesat berkembang sehingga kebutuhan dasar hingga taraf klinik juga tak heran dipandang sebagai kebutuhan belajar mahasiswa dan pembimbingnya. ${ }^{17,18}$

Mahasiswa yang mengambil blok IPK juga belajar bahwa IPC dapat membantu mahasiswa mengidentifikasi solusi layanan kesehatan berbasis teamwork dan pentingnya komunikasi dalam tim maupun dengan pasien. ${ }^{10,19}$ Alasan mengapa mahasiswa selain blok IPK tidak memilih topik tersebut sebagai topik berpengaruh karena tiadanya kekhususan IPC sebagai topik dalam blok elektif lainnya. Bila ditinjau lebih spesifik, sangat mungkin terdapat topik serupa dalam blok Paliatif dan blok Kedokteran Adiksi. Pendekatan serupa dilakukan dengan blok IPK, namun nama topik berbeda. Dalam blok Paliatif, mahasiswa diajak untuk memberikan layanan berbasis teamwork dan bilamana memungkinkan termasuk layanan dengan kolaborasi bidang lain. Dalam blok Kedokteran adiksi terdapat topik yang mengedepankan holistic and comprehensive view terhadap permasalahan adiksi, yang berarti relatif sama dengan IPC. Sementara itu, blok Entrepreneurship bidang kesehatan mempunyai tujuan hingga business plan development yang berbasis pada semangat menyelesaikan masalah dalam komunitas yang berkaitan dengan masalah kesehatan. Tentu hal ini tak akan lepas dari teamwork. Oleh karena itu, sangat mungkin pertanyaan mengenai kedua topik ini perlu dijelaskan dalam kuesioner Delphi sehingga keterbatasan respon para subjek dapat dihindari. Penulis menyadari letak keterbatasan penelitian ini pada pengambilan pendapat Delphi mengenai topik IPC ini yang perlu dijelaskan dengan detil secara berdialog.

Penelitian ini menunjukkan bahwa topik-topik dalam blok IPK dapat diimplementasikan di beberapa blok elektif lain terutama yang dinyatakan berpengaruh bagi praktik kedokteran dan kesehatan. Hasil penelitian ini dapat juga diimplementasikan di fakultas kedokteran universitas lain. Topik blok IPK mengenai penelitian pendidikan kedokteran dapat dijadikan pertimbangan untuk diimplementasikan di blok lain, karena pengetahuan mengenai kemajuan penelitian pendidikan kedokteran juga berarti memfasilitasi pengetahuan perkembangan kedokteran, kesehatan, dan pengobatan pada penyakit-penyakit lainnya.

\section{KESIMPULAN}

Topik blok IPK yang paling memberikan pengaruh pada perilaku mahasiswa kedokteran dan lulusan kedokteran dalam praktik klinis adalah edukasi personal, penelitian pendidikan kedokteran, dan profesionalisme. Selain tiga topik tersebut, topik tambahan yang berpengaruh menurut mahasiswa kedokteran yang mengambil blok IPK adalah interprofessional collaboration.

\section{DEKLARASI KEPENTINGAN}

Penulis menyatakan bahwa penelitian ini tidak memiliki konflik kepentingan apapun.

\section{INFORMASI KONTRIBUSI TENTANG PENGARANG}

$\mathrm{G}$ adalah penulis utama dari artikel ini. ER adalah penulis korespondensi dari artikel ini, mengajar di blok elektif Ilmu Pendidikan Kedokteran, dan pembimbing utama dalam membimbing $G$ dari awal hingga akhir penelitian.

\section{UCAPAN TERIMAKASIH}

Tim peneliti mengucapkan terima kasih kepada pimpinan Medical Education Unit dan Blok Ilmu Pendidikan Kedokteran Fakultas Kedokteran \& Ilmu Kesehatan Universitas Katolik Indonesia Atma Jaya yang memberikan informasi dan bersedia bekerja sama dalam penelitian dan penulisan artikel ini. 


\section{DAFTAR PUSTAKA}

1. Weaver SJ, Dy SM, Rosen MA. Team-training in healthcare: a narrative synthesis of the literature. BMJ Qual Saf. 2014;23(5):359-72.

2. Belfrage A, Grotmol KS, Lien L, Moum T, Wiese RV, Tyssen R. Medical school predictors of later perceived mastery of clinical work among Norwegian doctors: a cohort study with 10-year and 20-year follow-up. BMJ Open. 2017;7(9):e014462.

3. Hamilton AL, Kerins J, MacCrossan MA, Tallentire VR. Medical students' non-technical skills (Medi-StuNTS): preliminary work developing a behavioural marker system for the non-technical skills of medical students in acute care. BMJ STEL. 2018;bmjstel-2018-000310.

4. Muddiman E, Bullock AD, Hampton JM, Allery L, MacDonaldJ, WebbKL, etal.Disciplinaryboundaries and integrating care: using Q-methodology to understand trainee views on being a good doctor. BMC Med Educ. 2019;19(1):59-59.

5. Jorm C, Roberts C, Lim R, Roper J, Skinner C, Robertson J, et al. A large-scale mass casualty simulation to develop the non-technical skills medical students require for collaborative teamwork. BMC Med Educ. 2016;16:83-83.

6. Renschler L, Rhodes D, Cox C. Effect of interprofessional clinical education programme length on students' attitudes towards teamwork. J Interprof Care. 2016;30(3):338-46.

7. Wilson AJ, Palmer L, Levett-Jones T, Gilligan C, Outram S. Interprofessional collaborative practice for medication safety: Nursing, pharmacy, and medical graduates' experiences and perspectives. J Interprof Care. 2016;30(5):649-54.

8. Al-Abdulrazzaq D, Al-Fadhli A, Arshad A. Advanced medical students' experiences and views on professionalism at Kuwait University. BMC Med Educ. 2014;14:150.

9. Premkumar K, Vinod E, Sathishkumar S, Pulimood AB, Umaefulam V, Prasanna Samuel P, et al. Selfdirected learning readiness of Indian medical students: a mixed method study. BMC Med Educ. 2018;18(1). Available from: https://bmcmededuc. biomedcentral.com/articles/10.1186/s12909-0181244-9.
10. Palis A, Quiros P. Adult learning principles and presentation pearls. Middle East African J Ophthalmol. 2014;21(2):114-22.

11. Swanwick T, Forrest K, O'Brien BC. Understanding Medical Education: Evidence, Theory, and Practice. John Wiley \& Sons; 2019. 598 p.

12. Ishikawa $\mathrm{H}$, Son D, Eto M, Kitamura K, Kiuchi T. Changes in patient-centered attitude and confidence in communicating with patients: a longitudinal study of resident physicians. BMC Med Educ. 2018;18(1):20-20.

13. Hudson JN, Lethbridge A, Vella S, Caputi P. Decline in medical students' attitudes to interprofessional learning and patient-centredness. Med Educ. 2016;50(5):550-9.

14. Gonzalo JD, Wolpaw D, Graaf D, Thompson BM. Educating patient-centered, systems-aware physicians: a qualitative analysis of medical student perceptions of value-added clinical systems learning roles. BMC Med Educ. 2018;18(1):248-248.

15. Oswald A. Can we model trust and humility to help students make meaning of patient-centred care and interprofessional learning? Med Educ. 2016;50(5):506-8.

16. Ji YA, Nam SJ, Kim HG, Lee J, Lee S-K. Research topics and trends in medical education by social network analysis. BMC Med Educ. 2018;18(1):222.

17. Teodorczuk A, Yardley S, Patel R, Rogers GD, Billett S, Worley P, et al. Medical education research should extend further into clinical practice. Med Educ. 2017;51(11):1098-100.

18. Wood W, McCollum J, Kukreja P, Vetter IL, Morgan CJ, Hossein Zadeh Maleki A, et al. Graduate medical education scholarly activities initiatives: a systematic review and meta-analysis. BMC Med Educ [Internet]. 2018 [cited 2019 Jun 14];18(1). Available from: https://bmcmededuc. biomedcentral.com/articles/10.1186/s12909-0181407-8.

19. DiGioia AM, Greenhouse PK. Creating value with the patient- and family-centered care methodology and practice: what trainees need to know, why, and strategies for medical education. AMA J Ethics. 2016;18(1):33-9. 